\title{
THE SEED BANK DYNAMICS OF TWO DIFFERENT FOREST TYPES IN SOUTHERN SRI LANKA
}

\author{
P.A. Sunil, M.K.T.K. Amarasinghe \& R.Senaratne \\ Department of Crop Science, Faculty of Agriculture, \\ University of Ruhuna
}

The floristic composition and regeneration potential of natural forests in wet zone (Wilpita) and dry zone (Hambanthota) was investigated by sampling in the top $10 \mathrm{~cm}$ of the soil using special design samples $(30 \mathrm{~cm} * 30 \mathrm{~cm} * 10 \mathrm{~cm})$ along the transects and enumcrating the number of seedlings emerge from the soil during the period of two months. The seedlings were transferred into poly bags once a week and allowed to grow for few months to determine the floristic composition.

The mean number of seeds germinated per square meter in Wilpita in Hambanthota were 162 and 146 respectively. The composition of the seedlings from Wilpita and Hambanthota forests was not similar, though the population density was generally higher in the Wilpita forests. The floristic composition at the Wilpita forests was observed and Alstonia macrophyla (Hawarinuga), Macaranga Peltcta (Kande), Trema orientalis (Gedumba) and Melastoma malabathricum (Bovitiya) were prominent species among the tree species. Affinity analysis showed that the Alstonia was the most prominent tree species in Wilpita forest. There was no significant difference observed in the number of seedlings per square meter among the samples collected along the transects.

This study shows that the regeneration potential of the rain forests in the wet zone (Wilpita) is much higher than forests in the dry zone.

Proceedings of the Eighth Annual Forestry and Eitvironment Symposium 2002 of the Department of Forestry and Environmental Science, Uni ersity of Sri Jayewardenepura, Sri Lanka 